\title{
The Relationship Between Alzheimer's Disease, Parkinson's Disease and Motor Neuron Disease
}

\author{
Donald B. Calne and Andrew Eisen
}

\begin{abstract}
We argue against the dominant status assigned to conventional microscopy in the categorization of disorders such as Alzheimer's disease, Parkinson's disease and ALS. As an example we criticize the emphasis that has been placed on correlating the presence of Lewy bodies with the diagnosis of Parkinson's disease. In essence, we submit that Parkinson's disease can exist without Lewy bodies, and Lewy bodies can exist without Parkinson's disease. Nevertheless, we consider that the newer techniques available to histology have led to an important concept that constitutes a shared feature for Alzheimer's disease. Parkinson's disease and ALS; they are all characterized by the deposition of cytoskeletal debris in tissue, so they may perhaps be collectively termed the "Cytoskeletal Disorders".

RÉSUMÉ: Relation entre la maladie d'Alzheimer, la maladie de Parkinson et la maladie du neurone moteur Nous nous objectons au statut privilégié dont jouit la microscopie conventionnelle dans le cataloguage d'affections telles que la maladie d'Alzheimer, la maladie de Parkinson et la sclérose latérale amyotrophique (SLA). À titre d'exemple, nous critiquons l'amphase qui a été mise sur la corrélation de la présence des corps de Lewy avec le diagnostic de la maladie de Parkinson. Essentiellement, nous proposont que la maladie de Parkinson peut exister sans corps de Lewy et que les corps de Lewy peuvent exister sans maladie de Parkinson. Néanmoins, nous considérons que les techniques récentes qui sont disponibles en histologie ont mené à un concept important qui représente une caractéristique commune à la maladie d'Alzheimer, à la maladie de Parkinson et à la SLA; elles sont toutes caractérisées par des dépôts de débris du cytosquelette dans les tissus, de telle sorte qu'elles pourraient peut-être être appelées collectivement les "Maladies du Cytosquelette".
\end{abstract}

Can. J. Neurol. Sci. 1989; 16:547-550

Normal aging of the central nervous system is heterogeneous, severe attrition taking place in some regions, whereas others are relatively spared. Areas that undergo neuronal loss with the passage of time coincide with those regions that are the focus of neuronal loss in the most common degenerative diseases of the brain in late life: Alzheimer's disease, Parkinson's disease and motor neuron disease. Is this coincidence? We and others have proposed that a similar type of pathogenesis underlies Alzheimer's disease, Parkinson's disease and motor neuron disease. There may well be multiple etiological agents engaging this shared mechanism of neuronal damage.

As a first step in examining the relationship between Alzheimer's disease, Parkinson's disease and motor neuron disease, it is appropriate to pose the question "How are these diseases to be defined?" This is not a simple question. Over the last century microscopic analysis of pathological material has generally received major emphasis in categorizing diseases. Parkinson's disease has become tied to the Lewy body,
Alzheimer's disease has become associated with a high brain concentration of plaques and tangles and motor neuron disease is less consistently linked to the Bunina body. Is this dominant status assigned to microscopic appearance justified?

\section{NeUROPATHOLOGY}

Classical clinical-pathological correlations have led to the emergence of widely accepted views that have become sufficiently entrenched to attain the status of orthodox neuropathological concepts with profound implications for our understanding of disease processes. Justification for designating microscopic appearance as the crucial feature that characterizes a disease derives from the unassailable body of knowledge that certain types of tissue changes are universally and selectively linked to specific diseases; for example the Negri body was an irrefutable marker for rabies. However, problems arose where microscopy was not a sufficiently sharp tool to discriminate

From the Belzberg Laboratory of Clinical Neuroscience and Division of Neurology, Department of Medicine, University Hospital - U.B.C. Site, Vancouver

Reprint requests to: Dr. D. Calne, Belzberg Laboratory of Clinical Neuroscience, Division of Neurology, Department of Medicine, University Hospital, U.B.C. Site, 2211 Wesbrook Mall, Vancouver, British Columbia, Canada V6T IW5 
between nosological options; phenomena such as chromatolysis and gliosis became accepted as entirely non-specific.

In this context, degenerative diseases of the nervous system occupy an intermediate position such that opinions on the specificity of their pathology have been widely divergent. Neurofibrillary degeneration, senile plaques, and Lewy bodies are all difficult to interpret. Analysis is confounded by the firm observation that all of these neuronal changes are seen in some elderly subjects without symptoms. We propose to take one example of a possible morphological marker of disease, the Lewy body, and review the evidence for and against assigning it the status of a hallmark. This exercise is of importance from two viewpoints: 1) A marker may be employed as the definitive criterion for diagnosis. 2) A hallmark may become the focus for etiological analysis in the hope that it holds some clues to causation.

\section{The Lewy Body and Idiopathic Parkinsonism}

In 1913 Lewy described concentric eosinophilic hyaline cytoplasmic inclusion bodies in the substantia innominata of patients with idiopathic parkinsonism. ${ }^{1}$ Subsequently the association of Lewy bodies with the pigmented nuclei of the brainstem became established. ${ }^{2,3}$ However, Lewy bodies were also reported in $4-5 \%$ of subjects who did not have the clinical features of Parkinson's disease. ${ }^{4,5}$ Regional localization of Lewy bodies became steadily extended, to include non-pigmented brainstem nuclei, the hypothalamus, the cerebral cortex, the lateral horns of the thoracic cord, the sympathetic ganglia, and the parasympathetic ganglia. 6,7 The recent introduction of ubiquitin staining has led to the identification of Lewy bodies in many settings where they were not readily seen in conventional histology, including the motor neurons in the anterior horns of the spinal cord.

There can be no question, from the literature published over many years, that most cases of idiopathic parkinsonism have Lewy bodies, and that they occur most consistently in the area that is known to bear the brunt of neuronal loss in this disorder, the substantial nigra. If Lewy bodies are a diagnostic feature of the disorder, however, it should be possible to show that they always occur in idiopathic parkinsonism, and that they do not occur in other settings. Reference has already been made to the confirmed finding of Lewy bodies in 4-5\% of subjects who have no clinical evidence of idiopathic parkinsonism. This has been explained by postulating that the Lewy bodies represent subclinical evidence of idiopathic parkinsonism. Such an hypothesis is scarcely testable, since the detection of normal subjects with Lewy bodies cannot occur prior to death, which allows little opportunity for follow up.

\section{Lewy Bodies in the Normal Senescent Nervous System}

The relationship between idiopathic parkinsonism and normal aging of the nervous system has long intrigued those searching for an etiology. All the published accounts of Lewy bodies in subjects without the clinical features of parkinsonism indicate that the prevalence of Lewy bodies increases with the passage of time. ${ }^{8-12}$ The figures vary in detail, but the trend is from less than $5 \%$ below the age of 50 years, to over $10 \%$ beyond the age of 60 years. The prevalence of idiopathic parkinsonism is lower, but it does rise substantially in late life. ${ }^{13}$ These observations suggest that there may be shared factors contribut- ing to 1) the normal heterogeneous loss of neurons in the senescent nervous system and 2) the loss of neurons that occurs in idiopathic parkinsonism.

\section{Disorders with Lewy Bodies other than Idiopathic Parkinsonism}

In attempting to determine whether Lewy bodies can be regarded as specific markers for idiopathic parkinsonism, it is clearly relevant to consider their prevalence in other disorders. Woodard 14 has suggested that there is an increased prevalence of Lewy bodies in Alzheimer's disease and this has been confirmed recently. In Gibb's series, ${ }^{8}$ Lewy bodies occurred in 7\% of normal subjects over the age of 60 years, while the prevalence in Alzheimer's disease was $14-22 \%$ in the same age group. Gibb also gives figures of $14 \%$ with Lewy bodies in this age range for multiple system atrophy (including striatonigral degeneration and olivopontocerebellar atrophy). In addition, Lewy bodies are seen in progressive supranuclear palsy 15 and Hallervorden Spatz disease, ${ }^{16}$ though comparable figures are not available. Recently, Lewy bodies have been found in Guamanian Lytico-Bodig and in patients with motor neuron disease (ALS). ${ }^{17}$ Here again quantitative comparisons are not possible because of the limited number of age matched controls. Finally, it is relevant to mention that structures very similar to Lewy bodies have been seen in elderly monkeys exposed to the nigral toxin, MPTP, 18 and in patients with postencephalitic parkinsonism and neurolathyrism. 19

\section{Idiopathic Parkinsonism without Lewy Bodies}

In order to elucidate the relationship between idiopathic parkinsonism and Lewy bodies, it is clearly relevant to search for patients who have the clinical features of the disorder in the absence of Lewy bodies. The older literature reporting this quest is conflicting, but in a recent study, Rajput ${ }^{20}$ reported 4 patients who, on clinical grounds, were diagnosed as having classical idiopathic parkinsonism; none of these had Lewy bodies. They did, however, have other evidence of nigral pathology, notably neurofibrillary tangles.

\section{The Nature of Lewy Bodies}

In summary, the evidence accumulating over this century indicates that: 1) Lewy bodies are frequently seen in subjects without neurological deficits, prevalence increasing substantially over the age of 60 years. 2) Lewy bodies are far more frequent in idiopathic parkinsonism than in controls, and while they can occur at many sites, they are most consistently concentrated in the region that appears to be the primary site of neuronal degeneration in this disorder, the substantia nigra. 3) Lewy bodies occur in certain other degenerative neurological diseases, with a frequency far in excess of controls. 4) Idiopathic parkinsonism can exist without Lewy bodies.

In formulating these facts, the terms "Lewy body" (round eosinophilic cytoplasmic inclusion with halo) and "idiopathic parkinsonism" are employed according to common usage. It is easy to see how definitions could be manipulated to create a self-fulfilling prophesy and distort the straight forward observations that we have reviewed.

From the evidence cited, we conclude that, while there is a close association between Lewy bodies and idiopathic parkinsonism, it is incorrect to regard Lewy bodies as the "sine qua 
non" of a specific Parkinson's disease. A more appropriate concept might be that the Lewy body is the morphological indicator of a certain type of neuronal deterioration that occurs with particularly high prevalence in the substantial nigra of patients with idiopathic parkinsonism; similar degeneration can, however, occur in other locations and in other disorders. The situation would be analogous to the presence of oligoclonal bands in the cerebrospinal fluid of patients with multiple sclerosis; these bands are highly correlated with the disease, and they may shed some light on etiological mechanisms, but they are not specific or essential for the diagnosis.

What, then, can the Lewy body tell us about the neuronal degenerative process that takes place in so many cases of idiopathic parkinsonism? Examination by electronmicroscopy indicates that Lewy bodies are made up of filamentous material, and immunohistological studies indicate that this is neurofilament. ${ }^{21}$ Can such information be employed to guide the search for etiology? Certainly, current hypothetical causal agents for cell destruction, such as free radicals or excitatory amino acids, might be evaluated for their ability to disrupt the organization of neurofilaments, and it might be of interest to compare and contrast idiopathic parkinsonism with other disorders that manifest morphological evidence of cytoskeletal decay expressed, for example, in the form of neurofibrillary tangles. The similarities between idiopathic parkinsonism, ALS, Alzheimer's disease, progressive supranuclear palsy and Guamanian Lytico-Bodig might justify introduction of the unifying term "cytoskeletal disorders", analogous to such entities as the "lysosomal diseases" or the "mitochondrial diseases."

\section{The Clinical Picture}

In considering the relationship between idiopathic parkinsonism, Alzheimer's disease, and ALS it is clearly relevant to examine the overlap of clinical features. No satisfactory epidemiological survey has been performed to establish the extent of overlap between these disorders in an unselected population. However, we have undertaken a retrospective analysis of the last 121 patients seen with a diagnosis of ALS. Since 1985 we have examined 121 patients with sporadic, electromyographically confirmed ALS. Five had associated idiopathic parkinsonism, and six had dementia. The age and sex distribution of these patients is summarized in Table 1 , which also shows time relationship in onset of clinical features.

The findings indicate a much higher degree of overlap than would be anticipated by the chance occurrence of more than one

Table 1: Details of Patients with Overlapping Syndromes. In All Patients, ALS Followed Dementia or Parkinsonism After an Interval Recorded in Each First Column. The Second Column Records the Age at Which ALS Presented.

\begin{tabular}{|c|c|c|c|c|c|}
\hline \multicolumn{3}{|c|}{ Dementia } & \multicolumn{3}{|c|}{ Parkinsonism } \\
\hline $\begin{array}{c}\text { Interval } \\
\text { (years) }\end{array}$ & $\begin{array}{c}\text { Age } \\
\text { (years) }\end{array}$ & Sex & $\begin{array}{c}\text { Interval } \\
\text { (years) }\end{array}$ & $\begin{array}{c}\text { Age } \\
\text { (years) }\end{array}$ & Sex \\
\hline 3.4 & 64 & $\mathrm{~F}$ & 5.3 & 71 & $\mathrm{~F}$ \\
\hline 4.2 & 77 & $\mathrm{M}$ & 6.7 & 79 & $\mathrm{M}$ \\
\hline 2.6 & 55 & $\mathrm{~F}$ & 4.4 & 73 & $\mathbf{M}$ \\
\hline 5.8 & 63 & $\mathrm{~F}$ & 3.8 & 53 & $\mathrm{M}$ \\
\hline 1.7 & 68 & $\mathrm{~F}$ & 0.7 & 57 & $F$ \\
\hline 4.8 & 57 & $\mathrm{M}$ & & & \\
\hline
\end{tabular}

common neurological disorder in the same age group. This point emerges from Table 2. Overlap between ALS, parkinsonism and dementia might be commoner if it were not that when ALS is the initial component, rapid progression leading to death usually precludes development of the other two.

However, any retrospective, hospital based study has limitations, and in order to confirm or refute the impression gained from our study it is desirable to design a prospective multicentre analysis of unselected subjects.

Firmer evidence of clinical overlap derives from the association between parkinsonism and dementia; some $30 \%$ of patients with idiopathic parkinsonism have dementia.22 While some have subdivided dementia into "cortical" and "subcortical" types, this classification is not universally accepted, and in many respects the dementia associated with idiopathic parkinsonism resembles that occurring in Alzheimer's disease.

\section{The Definition of Diseases}

The problem of defining diseases is not simply a semantic exercise, for how we define a disease has major implications for the search for etiology. We contend that the designation of a morbid entity as a "disease" should be based upon consideration of: 1) causation, 2) pathology, 3) clinical features, 4) age distribution, 5) sex distribution, 6) geographical distribution, 7) natural history, and 8) response to treatment. For Parkinson's disease, Alzheimer's disease and ALS there are major areas of ignorance relating to too many aspects of their nature for the designation "disease" to be justified. This dilemma has recently been explored in the case of idiopathic parkinsonism. Papers entitled "Is there a Parkinson's disease?" and "Is Parkinson's disease one disease?" independently reached the conclusion that we are not justified in assuming that Parkinson's disease is a single morbid entity.

\section{CONCLUSION}

In conclusion, we argue that Alzheimer's disease, Parkinson's disease and ALS are idiopathic syndromes and for each there may well be several causal agents. However, the overlap between these conditions, and their resemblance to neurological aging suggest that the pathogenesis involves a similar type of process - just as a wide variety of organisms can cause meningitis or encephalitis, but all share the common mechanism of destroying tissue by a combination of infection and inflammation.

Table 2: Number of Subjects with Dementia or Parkinsonism Expected Among 121 ALS Patients at a Mean Age of 65 Years. Figures Derived From Age Specific Prevalence Rates Recorded by Schoenberg 23 and Jorm et al. 24

\begin{tabular}{lccc}
\hline $\begin{array}{c}\text { Prevalence } \\
\text { Expected per 100,000 }\end{array}$ & $\begin{array}{c}\text { Prevalence } \\
\text { Expected per 121 }\end{array}$ & $\begin{array}{c}\text { Prevalence } \\
\text { found per 121 }\end{array}$ \\
\hline Dementia & 1500 & 1.8 & 6 \\
Parkinsonism & 500 & 0.6 & 5 \\
\hline
\end{tabular}




\section{REFERENCES}

1. Lewy FH. Zur pathologischen Anatomie der Paralysis agitans. Dtsch Zeitschr Nervenheil 1913; 50: 50-55.

2. Klaue R. Parkinsonsche Krankheit (Paralysis agitans) and postencephalitischer Parkinsonismus. Arch Psychiatr Nervenkr 1940; 111: $251-321$.

3. Greenfield JG, Bosanquet FD. The brain-stem lesions in Parkinsonism. J Neurol Neurosurg Psychiatry 1953; 16: 213226.

4. Lipkin LE. Cytoplasmic inclusions in ganglion cells associated with Parkinsonian states. Am J Pathol 1959; 35: 1117-1133.

5. Forno LS. Pathology of Parkinsonism: a preliminary report of 24 cases. J Neurosurg 1966; 24: 266-271.

6. Jager WA den $H$, Bethlem $J$. The distribution of Lewy bodies in the central and autonomic nervous systems in idiopathic paralysis agitans. J Neurol Neurosurg Psychiatry 1960; 23: 283-290.

7. Ditter SM, Mirra SS. Neuropathologic and clinical features of Parkinson's disease in Alzheimer's disease patients. Neurology 1987; 37: 754-760.

8. Gibb WRG. The epidemiology of Lewy bodies. In: Fahn S, Marsden CD, Goldstein M, Calne D, eds. Recent development in Parkinson's disease. Vol. II, Macmillan Healthcare Information, Florham Park, 1987; 1-14.

9. Hamada S, Ishii T. The Lewy body in the brain of the aged. Adv Neurol Sci 1963; 7: 184-186.

10. Hirai S. Ageing of the substantia nigra. Adv Neurol Sci 1968; 12: $845-849$.

11. Forno LS, Alvord EC. The pathology of parkinsonism. In: McDowell $\mathrm{FH}$, Markham $\mathrm{CH}$, eds. Recent Advances in Parkinson's Disease. Oxford: Blackwell, 1971: 120-161.

12. Tomonaga M. Neuropathology of the locus coeruleus: a semiquantitative study. J Neurol 1983; 230: 231-240.

13. Mutch WJ, Dingwall-Fordyce I, Downie AW, et al. Parkinson's disease in a Scottish city. Br Med J 1986; 292: 534-536.
14. Woodard JS. Clinico-pathologic significance of granulovacuolar degeneration in Alzheimer's disease. J Neuropathol Exp Neurol 1962; 21: 85-91.

15. Mori H, Yoshimura M, Tmoonaga M, et al. Progressive supranuclear palsy with Lewy bodies. Acta Neuropathol (Berl) 1986; 71: $344-346$

16. Williamson K, Sima AAF, Curry B, et al. Neuroaxonal dystrophy in young adults: a clinicopathological study of two unrelated cases. Ann Neurol 1982; 11: 335-343.

17. Leigh PN, Anderton BH, Dodson A, et al. Ubiquitin deposits in anterior horn cells in motor neuron disease. Neurosci Lett 1988; 93: 197-203.

18. Forno LS. Langston JW, DeLanney LE, et al. Locus ceruleus lesions and eosinophilic inclusions in MPTP-treated monkeys. Ann Neurol 1986; 20: 449-455.

19. Striefler M, Cohn DF, Hirano A, et al. The central nervous system in a case of neurolathyrism. Neurology 1977; 27: 1176-1178.

20. Rajput AH, Ryan MB, Uitti RJ, et al. Parkinsonism and neurofibrillary tangle pathology in pigmented nuclei. Ann Neurol 1989; 25: 602-606.

21. Goldman JE, Yen SH. Chin F-C, et al. Lewy bodies of Parkinson's disease contain neurofilament antigens. Science 1983; 221: 1082-1084.

22. Teravainen $H$, Hietanen $M$, Stoess1 J, Calne DB. Dementia in movement disorders. Can J Neurol Sci 1986; 13: 546-558.

23. Schoenberg BS. Environmental risk factors for Parkinson's disease: the epidemiologic evidence. Can J Neurol Sci 1987; 14: 407413.

24. Jorm AF, Korten AE, Henderson AS. The prevalence of dementia: a quantitative integration of the literature. Acta Psychiatr Scand 1987; 76: 465-479. 